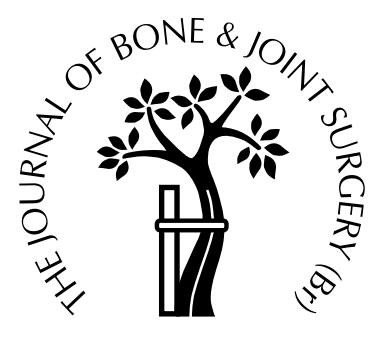

\title{
Degradation of hydroxyapatite coating on a well-functioning femoral component
}

\author{
N. Aebli, J. Krebs, D. Schwenke, H. Stich, P. Schawalder, J.-C. Theis \\ From the University of Otago, Dunedin, New Zealand
}

W

e carried out a histological study of a proximally hydroxyapatite (HA)-coated femoral component, retrieved after 9.5 years of good function. The HA coating had completely degraded. Bone was in direct contact with the titanium surface in all the areas which had been coated, with no interposing fibrous tissue. There were no signs of particles, third-body wear, adverse tissue reactions or osteolysis. Bone remodelling was evident by the presence of resorption lacunae; tetracycline labelling showed bone laid down six years after implantation.

The loss of the HA-coating had no negative effect on the osseo-integration of the stem. We conclude that the HA coating contributes to the fixation of the implant and that its degradation does not adversely affect the longterm fixation.

J Bone Joint Surg [Br] 2003;85-B:499-503.

Received 10 June 2002; Accepted after revision 9 January 2003

Because of its osteoconductive effect, hydroxyapatite (HA) coating has been used to improve the osseo-integration and thus fixation of uncemented implants for more than a decade. The midterm results of HA-coated total hip replacement have been very promising. ${ }^{1-3}$ The clinical use of HAcoated stems, however, remains a topic of debate because of concern about the stability of HA in the biological environ-

N. Aebli, MD, Senior Registrar

J. Krebs, DVSc, Visiting Research Fellow

D. Schwenke, PhD, Research Fellow

J.-C. Theis, FRACS, Associate Professor

Department of Orthopaedic Surgery, University of Otago, Dunedin, New Zealand.

H. Stich, Drhe, Histologist

The Dental School

P. Schawalder, DVSc, Professor

The Veterinary School

University of Bern, Switzerland.

Correspondence should be sent to Dr J Krebs at the MEM Research Centre for Orthopaedic Surgery, Institute for Surgical Technology and Biomechanics, University of Bern, PO Box 8354, CH-3001 Bern, Switzerland.

C)2003 British Editorial Society of Bone and Joint Surgery doi:10.1302/0301-620X.85B4.13605 \$2.00 ment and the consequences on osseo-integration in the long term. $^{4}$

HA on the surface of an implant may degrade as a result of mechanical abrasion or delamination, phagocytosis or dissolution due to low $\mathrm{pH}$, the presence of proteins or cellmediated resorption. ${ }^{5-13}$ There is evidence that HA particles may lead to cell-mediated osteolysis and subsequent loosening of the implant, or wear of the joint surfaces. ${ }^{14,15}$ Not all examples of the degradation of HA have been detrimental. New bone can form in direct contact with a metal surface as HA is degraded, creating an osseo-integrated surface. ${ }^{9}$ Furthermore, third-body wear does not seem to be more of a problem with HA-coated than with uncoated uncemented implants. ${ }^{16}$

Previous reports have documented the histological results of HA-coated stems retrieved after a maximum of 6.2 years. $^{9}$ Our study presents the radiological and histological results of a retrieved HA-coated stem 9.5 years after implantation.

\section{Case report}

A 61-year-old male farmer weighing $120 \mathrm{~kg}$ with chronic obstructive pulmonary disease and diabetes (type II), received a total hip arthroplasty for primary osteoarthritis of the right hip. The implants were an uncemented $13 \mathrm{~mm}$ ABG femoral stem and a $54 \mathrm{~mm}$ ABG I acetabular cup (Howmedica, Staines, UK) with a polyethylene liner. The femoral stem was made from titanium alloy (Ti6A14V). The proximal third of the stem had a macro-relief texture and was coated with commercially pure titanium (roughness between 3 and $4 \mu \mathrm{m} \mathrm{Ra}$ ) and subsequently with HA by vacuum plasma spraying to a thickness of $60 \mu \mathrm{m}$. The HA coating had a purity of more than $90 \%$, a crystallinity of approximately $75 \%$ and a Ca:P ratio of 10:6.

There were no complications after the surgery or during the follow-up period. Radiographs were taken immediately after operation and four years later. The patient received long-term prophylactic treatment with tetracycline for pulmonary infection, six years after the surgery. He died from cardiac arrest, after the prosthesis had been in situ for 9.5 years and functioning very well. Permission to retrieve the prosthesis had been obtained from the patient and from his next of kin. 


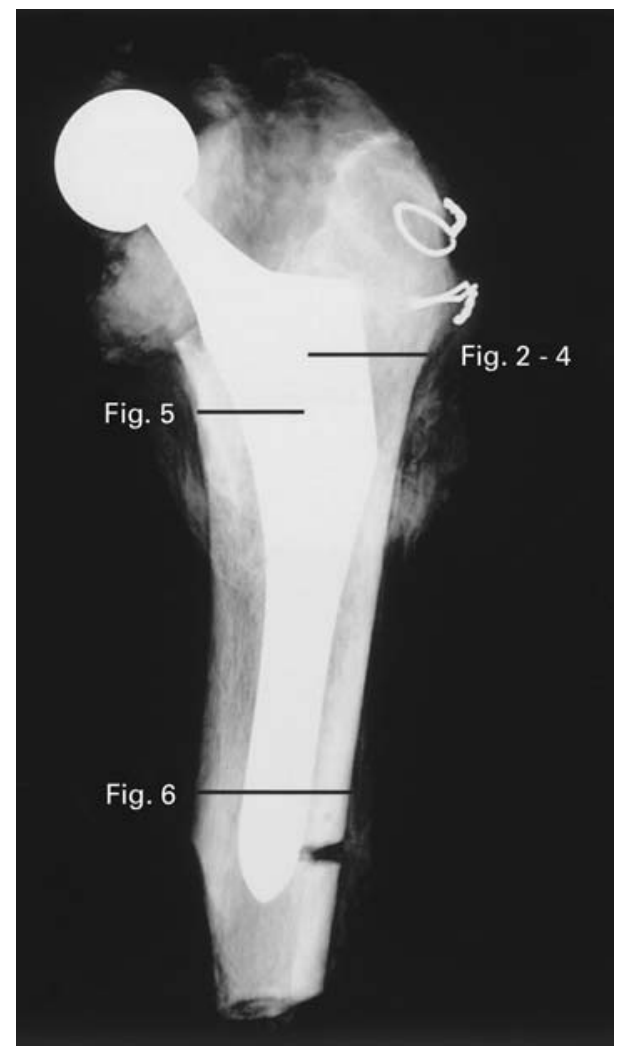

Fig. 1

Radiograph of the prosthesis fixed within the shaft of the retrieved femur indicating the areas from which the sections shown in Figures 2 to 6 have been taken.

Retrieval and processing. The proximal femur was removed en bloc at post mortem and fixed in $10 \%$ buffered formalin. The upper half of the femur, containing the whole stem, was radiographed before being cut into multiple blocks. Each specimen was later processed according to the technique described by Stich. ${ }^{17}$ Specimens were sectioned and ground down to a thickness of between 10 and $30 \mu \mathrm{m}$.

We took histomorphometric measurements from scanned light-microscopic photographs (original magnification x 6) using the computer software Corel Photopaint (Version 9; Corel Corporation, Ottowa, Canada). We determined the proportion of bone-implant contact from a calibrated grid (2 $\mathrm{x} 2 \mathrm{~mm}$ ) superimposed above the section image. Because of the small number of sections analysed these measurements are useful only as a rough guide.

\section{Results}

Both stem and cup were secure within the shaft of the femur and the acetabulum, respectively. There was no macroscopic evidence of loosening, metallosis on the inner surface of the joint capsule, or wear on the surface of the polyethylene inlay of the cup.

Radiological examination. The stem was well integrated, with no surrounding radiolucent lines (Fig. 1). During the

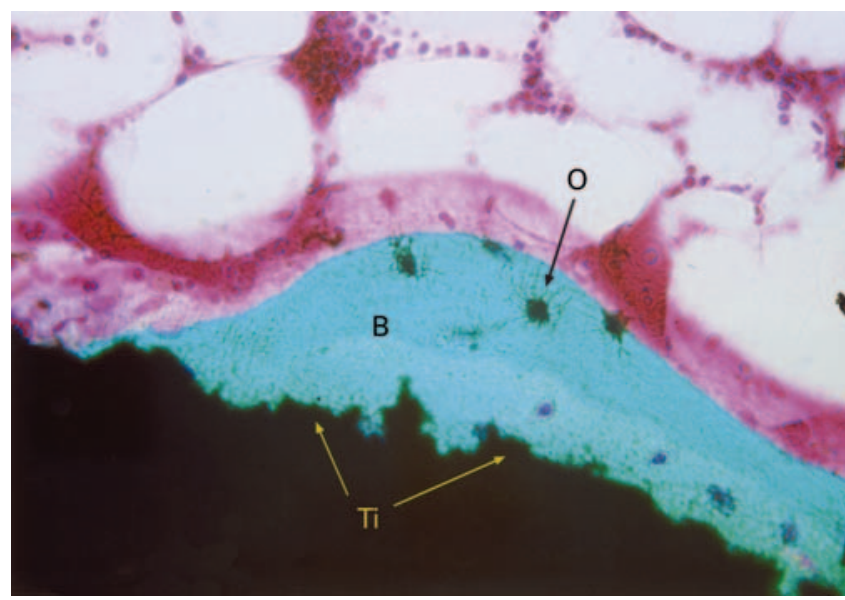

Fig. 2

Photomicrograph through zone 1 showing bone $(\mathrm{B})$ in direct contact with the rough titanium (Ti) surface $(\mathrm{O}$, osteocyte; Light Green and Basic Fuchsin x 150).

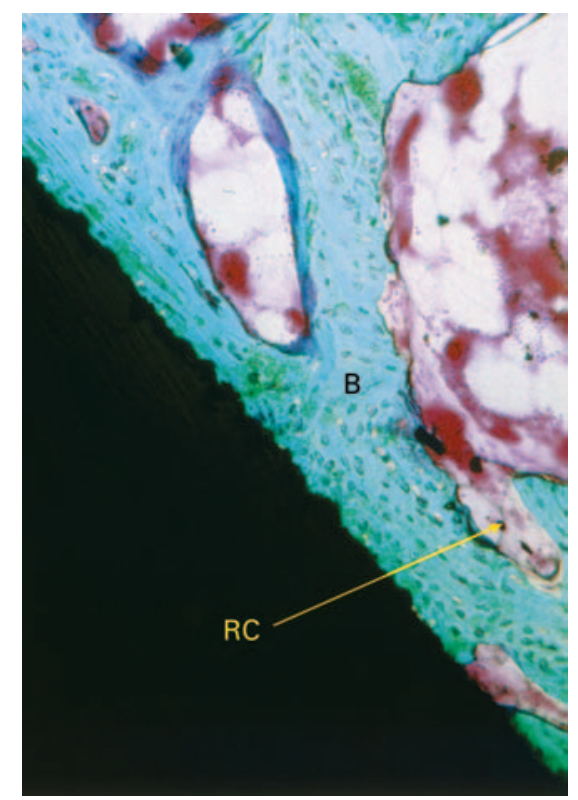

Fig. 3

Photomicrograph through zone 1 showing a remodelling canal $(\mathrm{RC})$ in a bone trabeculum (B) (Light Green and Basic Fuchsin x 50).

9.5 years since surgery it had subsided by $4 \mathrm{~mm}$, as measured from the shoulder of the prosthesis. There was slight corticalisation of the cancellous bone in Gruen zones 3 and 5 (Fig. 1). Bone in Gruen zone 6 seemed to be atrophic. These features were not observed on the radiographs taken at four years after operation. All other zones showed normal bone density.

Histological examination. All the sections of Gruen zones 1 and 7 which were analysed showed no sign of the HA coating remaining on the surface of the implant, indicating 


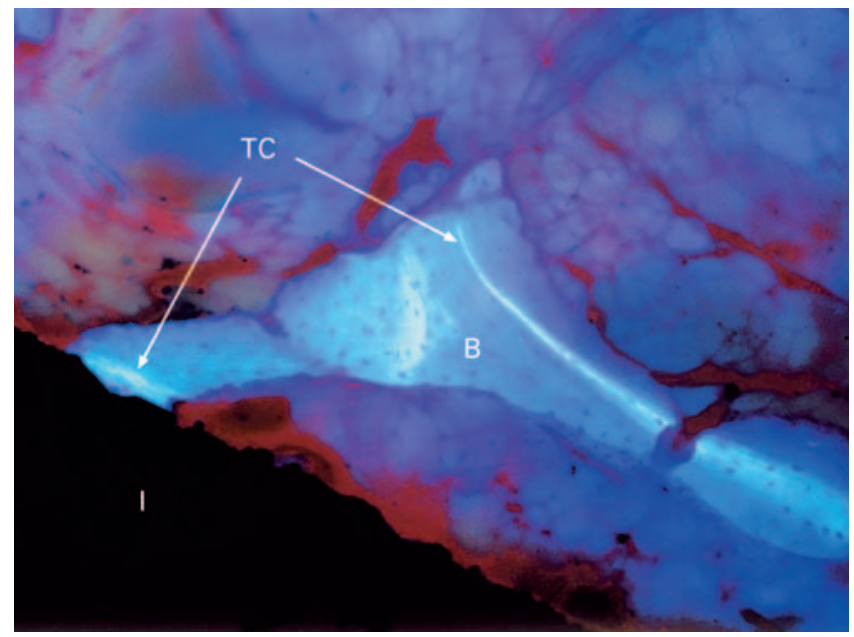

Fig. 4

Photomicrograph through zone 1 taken under ultraviolet light showing tetracycline (TC)-labelled bone (B) adjacent to the implant (I) ( x 20).

that it had been completely degraded. Bone trabeculae were in direct contact with the titanium surface in all areas from which the HA coating had been removed with no interposing fibrous tissue (Fig. 2), indicating a mechanically stable interface. The presence of resorption lacunae gave evidence of active remodelling (Fig. 3). The fact that remodelling continued well beyond the initial years after implantation was also demonstrated by the traces of tetracycline visible within the bone on microscopic views taken with ultraviolet light (Fig. 4). There were no wear particles or inflammatory cells in any section studied and no evidence of osteolysis. The surrounding bone was mildly atrophic in zones 1 and 7 . In the transitional region between zone 1 (distal) and zone 2 (proximal), the surrounding bone appeared to be hypertrophic. In zone 7, the cortex showed signs of cancellisation (Fig. 5). The 'fish-scale' macrotexture of the stem resulted in increased gaps between the surface of the implant and the surrounding bone; no bone had crossed these gaps. Bone-toimplant contact was approximately $23 \%$ in zone 7 (Fig. 5), $30 \%$ in zone 1 and $54 \%$ in the transitional region between zones 1 and 2.

In the distal Gruen zones 2 to 6 , an interposing fibrous tissue layer, which was quite thick in some areas, was seen between the bone trabeculae and the surface of the implant (Fig. 6). The proportion of bone-to-implant contact distally was approximately $7 \%$. There was no bone marrow in direct contact with the surface of the implant. There appeared to be a ring of comparatively dense bone in the peri-implant region (Fig. 6) where the bone trabeculae were orientated in a radial fashion. In zones 3 and 5, the surrounding bone was hypertrophic, but there was no hypertrophic bone (no reactive lines) distal to the tip of the stem. There was evidence of continuing active and previous bone remodelling by resorption lacunae and tetracycline staining. Cortical and cancellous bone atrophy seen on radiographs of zone 6 was

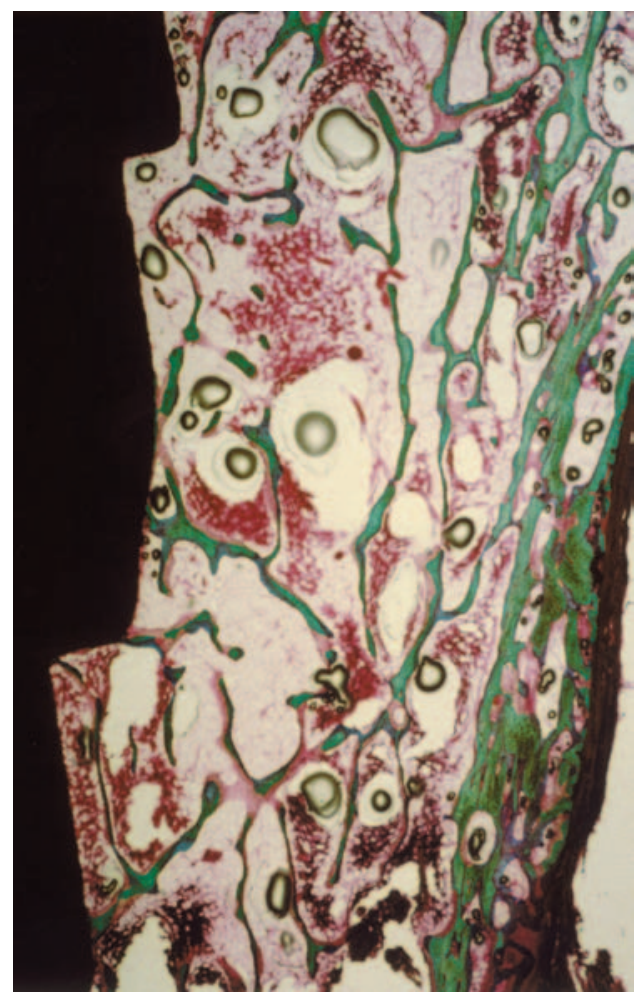

Fig. 5

Photomicrograph of a horizontal section through the calcar area showing cancellisation of the cortex. Approximately $23 \%$ of the surface is in contact with bone (Light Green and Basic Fuchsin x 1.25).

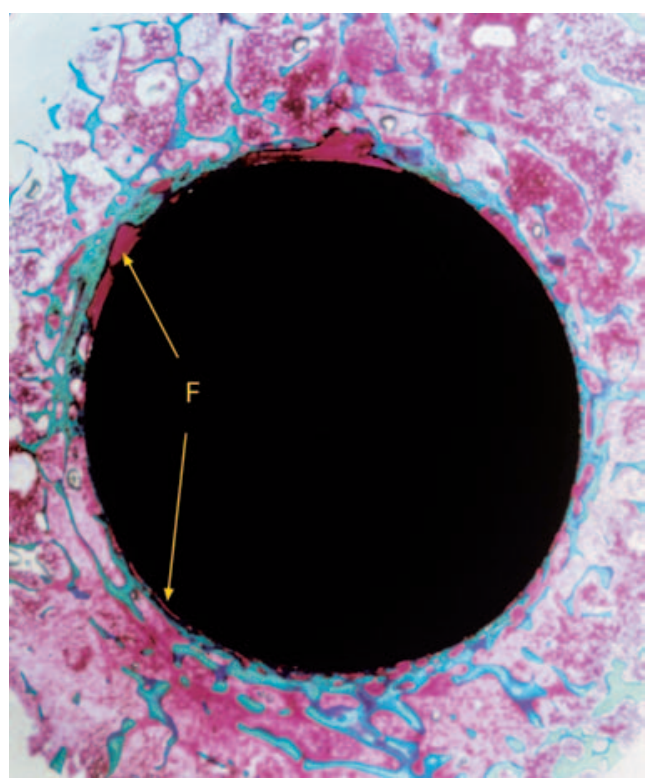

Fig. 6

Photomicrograph of horizontal section through zones 3 and 5. Most of the implant circumference is in contact with fibrous tissue (F) (Light Green and Basic Fuchsin $\mathrm{x}$ 1). 
also evident histologically and this suggests stress shielding.

\section{Discussion}

This investigation shows the radiological and histological appearances of a well-functioning, proximally HA-coated, femoral stem retrieved after 9.5 years. The HA coating had been completely removed and the proximal third of the prosthesis was well integrated with bone trabeculae. The design of the stem relies on proximal fixation, which is confirmed by the histological and radiological examinations.

The removal of the entire HA coating had no negative effect on osseointegration of the stem. The coating was not replaced by fibrous tissue on the surface of the implant and there were no adverse tissue reactions (eg. granulomata, osteolysis, etc) or third-body wear of the polyethylene liner associated with HA particles in the joint. This confirms findings of other retrieval studies. ${ }^{6,8,9,18-20}$ After degradation of the HA coating, bone trabeculae were in direct contact with the surface of the implant, as reported by other authors. ${ }^{9,19,21}$ It is therefore important that the surface of the metal underneath the HA coating encourages osseo-integration by virtue of its material and texture. ${ }^{9}$ In our implant, there was an underlying coating of commercially pure titanium with a rough surface which was ideal for this purpose. $^{22,23}$

The process of degradation of the HA coating seems to have occurred in the course of bone remodelling without loss of fixation, with osteoclasts probably playing a major role. It is likely that degraded amorphous HA at the interface induced new formation of bone. Bone remodelling depends on load transfer (Wolff's law), and is an ongoing process during the lifetime of the prosthesis. In our subject this was demonstrated by tetracycline staining of bone laid down six years after implantation. Some authors have reported that degradation only occurs in areas with no boneimplant contact. ${ }^{89}$ We found that all the HA coating had been removed, suggesting that degradation occurred in areas where there must have been bone-implant contact. Although the mechanisms of degradation of HA are speculative, phagocytosis and cell-mediated resorption (i.e. dissolution) are possible explanations.

The radiological and histological findings show proximal fixation and osseo-integration of the stem. Stress seemed to be uniformly distributed over the length of the stem and femur with little evidence of stress shielding. The concept of this proximally-coated stem is to provide proximal fixation by osseo-integration, allowing transfer of transitional load from proximal to distal. ${ }^{3}$

The average bone-implant contact of the originally coated part of the stem (34\%) was lower than in other retrieval studies ( $31 \%$ to $90 \%$ ). ${ }^{6,9,18}$ The time of implantation of these stems was shorter, between one and six years, and there was still some HA present. In our subject, the amount of bone on the surface of the implant may have been reduced in the natural process of bone remodelling. ${ }^{21}$ Coating resorption and bone remodelling have resulted in an extent of bone-implant contact which is typical of uncoated titanium implants. ${ }^{18,24}$

We have shown that the stem, distally, was covered by a layer of fibrous tissue. This tissue layer was demonstrated histologically, but was too thin to be detected radiologically as a radiolucent line. Radiographs therefore do not seem to be a reliable means of distinguishing between microscopic bone and fibrous tissue. ${ }^{25}$

We conclude that the loss of the HA coating has no negative effect in terms of loosening of the implant, adverse tissue reactions, osteolysis, third-body wear or formation of interposing fibrous tissue. Bone trabeculae were in direct contact with the underlying metal surface.

The authors wish to thank Professor A. Lussi for providing the bench space for the histological processing and Dr A. J. Tonino for reviewing the manuscript. They are also grateful for the funding provided by Stryker Europe, Scientific and Clinical Affairs.

Although none of the authors have received or will receive benefits for personal or professional use from a commercial party related directly or indirectly to the subject of this article, benefits have been or will be received but are directed solely to a research fund, foundation, educational institution, or other non-profit institution with which one or more of the authors is associated.

\section{References}

1. Capello WN, D'Antonio JA, Manley MT, Feinberg JR. Hydroxyapatite in total hip arthroplasty: clinical results and critical issues. Clin Orthop 1998;355:200-11.

2. Geesink RGT, Hoefnagels NHM. Six-year results of hydroxyapatitecoated total hip replacement. J Bone Joint Surg [Br] 1995;77-B:534-47.

3. Tonino AJ, Rahmy AI. The hydroxyapatite-ABG hip system: 5- to 7year results from an international multicentre study. J Arthroplasty 2000;15:274-82.

4. Söballe K, Overgaard S. Editorial. The current status of hydroxyapatite coating. J Bone Joint Surg [Br] 1996;78-B:689-91.

5. Bauer TW, Taylor SK, Jiang M, Medendorp SV. An indirect comparison of third-body wear in retrieved hydroxyapatite-coated, porous, and cemented femoral components. Clin Orthop 1994;298:11-8.

6. Bauer TW, Geesink RCT, Zimmerman R, McMahon JT. Hydroxyapatite-coated femoral stems: histological analysis of components retrieved at autopsy. J Bone Joint Surg [Am] 1991;73-A:1439-52.

7. Hardy DCR, Frayssinet P, Bonel G, et al. Two-year outcome of hydroxyapatite-coated prostheses: two femoral prostheses retrieved at autopsy. Acta Orthop Scand 1994;65:253-7.

8. Hardy DC, Frayssinet P, Krallis P, et al. Histopathology of a wellfunctioning hydroxyapatite-coated femoral prosthesis after 52 months. Acta Orthop Belg 1999;65:72-82.

9. Tonino AJ, Therin M, Doyle C. Hydroxyapatite-coated femoral stems: histology and histomorphometry around five components retrieved at post mortem. J Bone Joint Surg [Br] 1999;81-B:148-54.

10. Daculsi G, LeGeros RZ, Mitre D. Crystal dissolution of biological and ceramic apatites. Calcif Tissue Int 1989;45:95-103.

11. Klein CP, de Blieck-Hogervorst JM, Wolke JG, de Groot K. Studies of the solubility of different calcium phosphate ceramic particles in vitro. Biomaterials 1990;11:509-12.

12. Bender SA, Bumgardner JD, Roach, Bessho K, Ong JL. Effect of protein on the dissolution of HA coatings. Biomaterials 2000;21:299305.

13. Vaes G. Cellular biology and biochemical mechanism of bone resorption: a review of recent developments on the formation, activation, and mode of action of osteoclasts. Clin Orthop 1988;231:239-71.

14. Bloebaum RD, Dupont JA. Osteolysis from a press-fit hydroxyapatitecoated implant: a case study. J Arthroplasty 1993;8:195-202.

15. Bloebaum RD, Beeks D, Dorr LD, et al. Complications with hydroxyapatite particulate separation in total hip arthroplasty. Clin Orthop 1994;298:19-26. 
16. Bauer TW, Taylor SK, Jiang M, Medendorp SV. An indirect comparison of third-body wear in retrieved hydroxyapatite-coated, porous, and cemented components. Clin Orthop 1994;298:11-8.

17. Stich H. Herstellung der Schliffpräparate. In: Schroeder A, Sutter F, Krekeler G, eds. Orale Implantologie. Stuttgart: Thieme, 1988:109-15.

18. Coathup MJ, Blunn GW, Flynn N, Williams C, Thomas NP. A comparison of bone remodelling around hydroxyapatite-coated, porouscoated and grit-blasted hip replacements retrieved at post-mortem. $J$ Bone Joint Surg [Br] 2001;83-B:118-23.

19. Lintner F, Böhm G, Huber M, Scholz R. Does bone replacement occur after resorption of the HA coating at the titanium alloy surface after long term implantation of cementless hip- endoprostheses. Osteologie 2001;10:40-53.

20. Lintner F, Böhm G, Huber M, Scholz R. Histology of tissue adjacent to an HAC-coated femoral prosthesis: a case report. J Bone Joint Surg [Br] 1994;76-B:824-30.
21. Overgaard S, Søballe K, Josephsen K, Hansen ES, Bunger C. The role of different loading conditions on resorption of hydroxyapatite coating: evaluated by histomorphometric and stereological methods. $J$ Orthop Res 1996;14:888-94.

22. Buser D, Schenk RK, Steinemann S, et al. Influence of surface characteristics on bone integration of titanium implants: a histomorphometric study in miniature pigs. J Biomed Mater Res 1991;25:889-902.

23. Svehla M, Morberg P, Zicat B, et al. Morphometric and mechanical evaluation of titanium implant integration: comparison of five surface structures. J Biomed Mater Res 2000;51:15-22.

24. Bloebaum RD, Bachus KN, Rubman MH, Dorr LD. Postmortem comparative analysis of titanium and hydroxyapatite porous-coated femoral implants retrieved from the same patient: a case study. J Arthroplasty 1993;8:203-11.

25. Carlsson L, Rostlund T, Albrektsson B, Albrektsson T. Implant fixation improved by close fit: cylindrical implant-bone interface studied in rabbits. Acta Orthop Scand 1988;59:272-5. 